\title{
Usefulness of tissue Doppler-derived atrial electromechanical delay for identifying patients with paroxysmal atrial fibrillation
}

Kanako Akamatsu, Takahide Ito* (D), Masatoshi Miyamura, Yumiko Kanzaki, Koichi Sohmiya and Masaaki Hoshiga

\begin{abstract}
Background: Tissue Doppler imaging (TDI)-derived atrial electromechanical delay (AEMD) has been reported to be useful for detecting paroxysmal atrial fibrillation (PAF). However, its usefulness remains unknown when analyzed along with patients seemingly at high-risk for AF as controls. From this standpoint, we investigated whether AEMD would be of use for identifying patients with PAF.
\end{abstract}

Methods: We retrospectively analyzed TDI recordings to obtain AEMD in 63 PAF patients. Thirty-three patients with multiple cardiovascular risk factors (MRFs) but without history of AF and 50 healthy individuals served as disease and healthy controls, respectively. AEMD was defined as the time-interval between the electrocardiogram P-wave and the beginning of the spectral TDI-derived A' for the septal (septal EMD) and lateral (lateral EMD) sides of the mitral annulus.

Results: There was no significant difference in the left atrial volume index between PAF patients and disease controls $\left(28 \pm 9 \mathrm{~mL} / \mathrm{m}^{2}\right.$ vs. $\left.27 \pm 5 \mathrm{~mL} / \mathrm{m}^{2}\right)$. PAF patients had longer AEMD, particularly for the lateral EMD $(75 \pm 23$ $\mathrm{ms})$, compared with disease $(62 \pm 22 \mathrm{~ms}, P=0.009)$ and healthy $(54 \pm 24 \mathrm{~ms}, P<0.001)$ controls. Multivariate logistic regression analysis revealed that the lateral EMD (OR 1.25, 95\%Cl 1.03-1.52, $P=0.023)$, along with the left atrial volume index (OR 2.25, 95\% $1.44-3.51, P<0.001)$, was one of the significant independent associates of identifying PAF patients.

Conclusions: This cross-sectional study indicates that even analyzed together with MRFs patients, AEMD remains useful for identifying patients at risk for AF. Our results need to be confirmed by a large-scale prospective study.

Keywords: Atrial fibrillation, Tissue Doppler imaging, Atrial electromechanical delay

\section{Background}

Atrial fibrillation (AF) is one of the most common types of cardiac arrhythmias associated with increased cardiovascular morbidity and mortality. Risk factors of AF include advanced age, male gender, and presence of hypertension [1,2]. An increased left atrial (LA) volume index is also known as a strong predictor of AF [3-5]. It has been reported that the intra- and interatrial

\footnotetext{
* Correspondence: in3016@osaka-med.ac.jp

Department of Cardiology, Osaka Medical College, Takatsuki, Osaka 569-8686, Japan
}

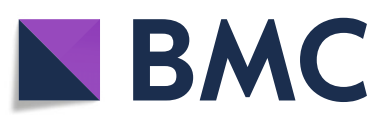

(c) The Author(s). 2020 Open Access This article is licensed under a Creative Commons Attribution 4.0 International License, which permits use, sharing, adaptation, distribution and reproduction in any medium or format, as long as you give appropriate credit to the original author(s) and the source, provide a link to the Creative Commons licence, and indicate if changes were made. The images or other third party material in this article are included in the article's Creative Commons licence, unless indicated otherwise in a credit line to the material. If material is not included in the article's Creative Commons licence and your intended use is not permitted by statutory regulation or exceeds the permitted use, you will need to obtain permission directly from the copyright holder. To view a copy of this licence, visit http://creativecommons.org/licenses/by/4.0/. The Creative Commons Public Domain Dedication waiver (http://creativecommons.org/publicdomain/zero/1.0/) applies to the data made available in this article, unless otherwise stated in a credit line to the data. conduction time, that is, the atrial electromechanical delay (AEMD), is an index of reflecting pathological changes of the atria [6-13]. AEMD can be measured not only by invasive electrophysiologic study but also by echocardiographic tissue Doppler imaging (TDI) [7-13]. Previous studies found that TDI-derived AEMD had an advantage to predict AF recurrence over LA diameter and P-wave duration [7]. On the other hand, AEMD was shown to be prolonged in various conditions other than cardiac disorders such as diabetes mellitus and ulcerative colitis [9-12]. However, most of the previous studies 
regarding AEMD were performed based on the comparison between patients in such diseased conditions and normal controls [9-12]; do not seem to include patients with similar clinical background to AF patients.

In the present study, we retrospectively investigated whether TDI-derived AEMD would be useful to identify patients who had been diagnosed with paroxysmal AF (PAF) in comparison with other variables known as strong predictors of AF including LA volume index. Specifically, this study included patients with multiple cardiovascular risk factors (MRFs) but without history of $\mathrm{AF}$ as disease controls in order to test the hypothesis that the ability of AEMD to identify PAF patients was maintained even when patients seemingly at high-risk for AF (i.e., MRFs patients) were included.

\section{Materials and methods}

\section{Study population}

We examined 75 PAF patients and 65 MRFs patients without history of AF, and 143 apparently healthy subjects, all of whom underwent transthoracic echocardiography from February 2012 through December 2018. Patients with previous cardiac surgery including pacemaker implantation, known coronary artery disease, left ventricular (LV) ejection fraction $<30 \%$, and those with dialysis treatment were excluded (Fig. 1). Patients who had echocardiographic images inadequate for assessing indispensable measures, described later, were also excluded.

PAF patients $(n=63)$ : All patients were scheduled for pulmonary vein isolation, with their cardiac rhythm being "sinus" during echocardiographic examinations.

Disease controls (MRFs patients) $(n=33)$ : This group of patients had been hospitalized in the department of neurology or neurosurgery in our institution under a diagnosis of non-lacunar ischemic stroke, transient ischemic attack, or peripheral artery occlusion. They were found neither to have AF detected on an automated cardiac rhythm monitor [14], nor to have apparent embolic sources detected by carotid ultrasound and transesophageal echocardiography.

Healthy controls $(n=50)$ : These individuals were screened for any cardiovascular disease in our outpatient department, and also showed normal results on the routine echocardiographic examination.

This study was approved by the ethics committee in Osaka Medical College with notification for guaranteed withdrawal of participants on the website providing means of "opt-out" (No. 2194-01).

\section{Standard echocardiography}

Transthoracic echocardiography was performed by experienced sonographers using commercially available ultrasound apparatus (Vivid 7 Dimensions or Vivid E9; GE Vingmed Ultrasound, Horten, Norway). During each

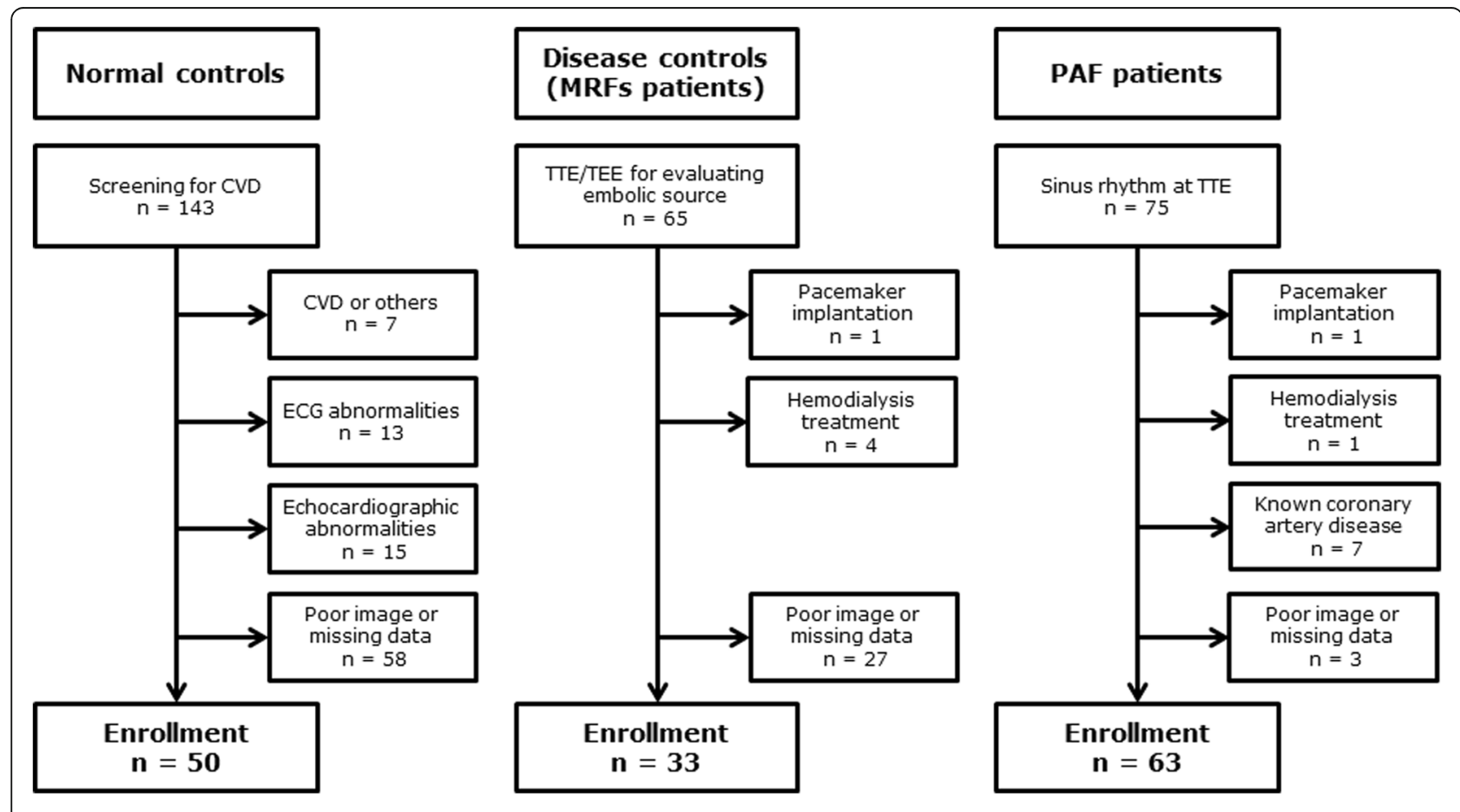

Fig. 1 Flowchart for the enrollment of study individuals. CVD, cardiovascular disease; TEE, transesophageal echocardiography; TTE, transthoracic echocardiography 
examination, one-lead electrocardiogram, usually the limb-lead II was recorded continuously. Under 2dimensional guidance in the parasternal view, LA diameter, LV end-diastolic dimension, and LV wall thickness were measured. LA volume was calculated by the disc method in the apical 2- and 4-chamber views and indexed by the body-surface area leading to LA volume index. LV ejection fraction was measured by the modified Simpson's rule. LV mass was calculated using the Devereux formula, and indexed by the body surface area ( $\mathrm{LV}$ mass index). LV mass index $\geq 115 \mathrm{~g} / \mathrm{m}^{2}$ in men and $\geq 95 \mathrm{~g} / \mathrm{m}^{2}$ in women were considered as the presence of LV hypertrophy [15].

For assessing LV diastolic function, pulsed Doppler LV inflow indices of early (E) and late filling (A) wave velocities, their ratio (E/A), and E-wave deceleration time were obtained. In the apical 4-chamber view, using the spectral type of TDI, early (E') and late (A') diastolic velocities were measured with the sample volume placed at the septal and lateral sides of the mitral annulus. The ratio of $E$ to $E^{\prime}$ (E/E') was used as a surrogate of LV filling pressure [16]. In the present study, A', meaning "velocity", averaged for both mitral annuli, was considered as LA systolic function.

\section{Measurement of AEMD}

AEMD was measured from the beginning of the electrocardiogram P-wave to the initial point of the spectral TDIderived A' as described previously [9-12] (Fig. 2). In this study, AEMD was obtained for the septal (septal EMD) and lateral (lateral EMD) sides of the mitral annulus. The time difference of the lateral to septal EMD was defined as intra-LA EMD as reported previously [12]. All AEMD measurements were performed by independent observers without knowledge of patients' background.
To assess interobserver variability of AEMD, 40 individuals were randomly selected and Bland-Altman plot analysis was performed (KA and TI). It was found that measurements were similar and statistically comparable with each other (Fig. 3). The mean difference was $1.9 \mathrm{~ms}$ (3.2\%) and the coefficient of variation was 4.9.

\section{Statistical analysis}

Continuous variables were expressed as mean \pm SD and categorical variables as percentages. Comparisons of categorical variables were made using the chi-square test or Fisher's exact test. Continuous variables across the 3 groups were compared using one-way analysis of variance or Wilcoxon test according to whether normally distributed or not, as tested by Welch test. Tukey's HSD test or Wilcoxon Each Pair test was applied for intergroup comparisons as appropriate. Univariate and multivariate logistic regression analysis were performed to predict significant variables for identifying PAF patients. The sensitivity and specificity of AEMD and other echocardiographic variables for identifying PAF patients were calculated by receiver operating characteristic (ROC) analysis. Comparisons of area under curves (AUCs) between models of ROC analysis were also performed. All analyses, except for ROC analysis, were performed using SPSS for Windows ver. 24.0 (IBM, Chicago, IL). For ROC analysis, JMP Pro ver. 13.0 (SAS Institute, Cary, NC) was used. $P<0.05$ was considered significant.

\section{Results}

Clinical and echocardiographic data of the study groups Demographic data of the study groups are summarized in Table 1. Age and gender distribution did not differ among the 3 groups. There was a trend toward increasing body mass index for PAF patients. Disease controls
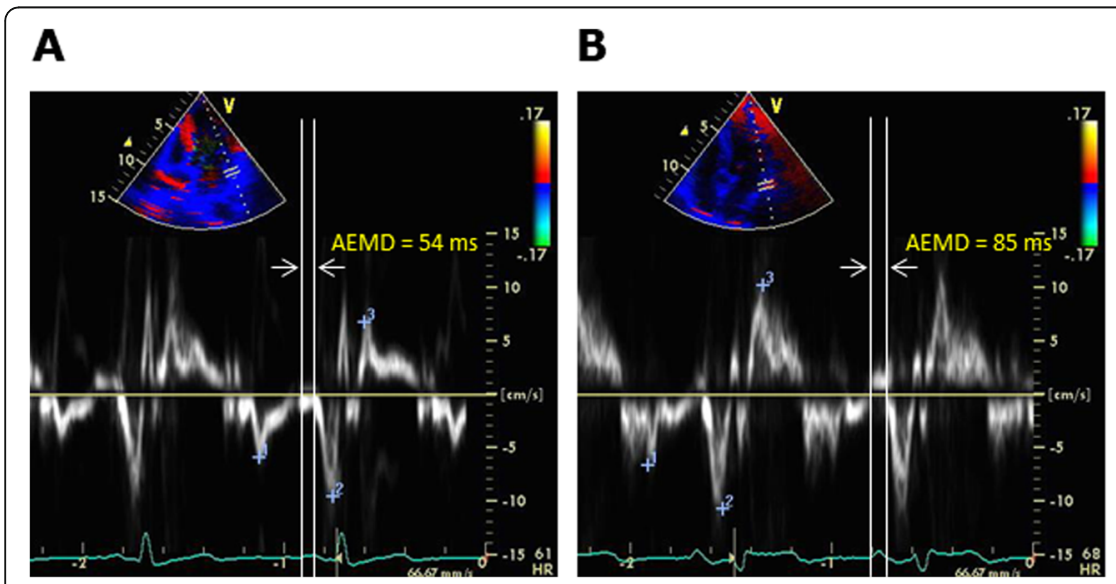

C

Fig. 2 Representative images of explanation how to measure AEMD obtained from: $\mathbf{a}$ a healthy subject; $\mathbf{b}$ a patient with multiple cardiovascular risk factors; c a PAF patient 

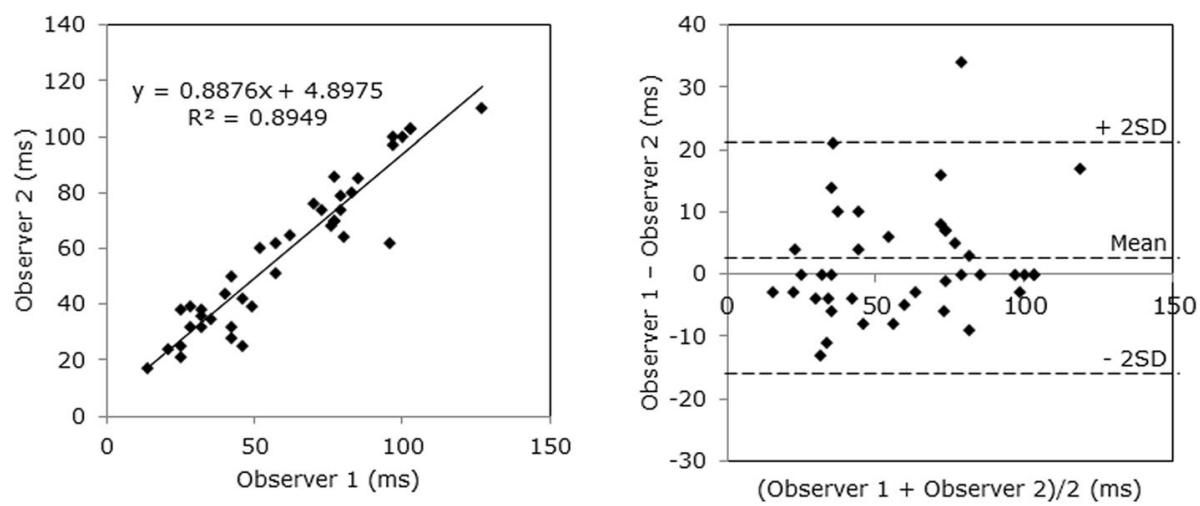

Fig. 3 Bland-Altman plot analysis for assessing interobserver variability of AEMD in randomly selected 40 subjects. See the text

had higher $\mathrm{CHADS}_{2}$ and $\mathrm{CHA}_{2} \mathrm{DS}_{2}$-VASc scores compared with PAF patients, primarily as a result of the patient selection. Antiarrhythmic drugs, exclusively being prescribed to PAF patients, included flecainide in 8 patients; verapamil in 4; amiodarone in 5; pilsicainide in 3; and cibenzoline in 1 .
Echocardiographic data are presented in Table 2. LV ejection fraction seemed to be preserved in all groups. There were no statistically significant differences in LA volume index or LV mass index between PAF patients and disease controls. Disease controls had a slight increase in E/E', but did not seem to be in heart failure condition.

Table 1 Demographic data of the study groups

\begin{tabular}{|c|c|c|c|c|}
\hline Parameters & $\begin{array}{l}\text { Healthy controls } \\
(n=50)\end{array}$ & $\begin{array}{l}\text { Disease controls } \\
(n=33)\end{array}$ & $\begin{array}{l}\text { PAF patients } \\
(n=63)\end{array}$ & $P$ \\
\hline Age (years) & $60 \pm 14$ & $66 \pm 15$ & $62 \pm 13$ & 0.21 \\
\hline Female, n (\%) & $19(38)$ & $12(36)$ & $17(27)$ & 0.41 \\
\hline Body mass index & $22.0 \pm 3.3$ & $23.1 \pm 4.1$ & $24.5 \pm 3.6+\S$ & $<0.001$ \\
\hline $\mathrm{CHADS}_{2}$ score & $0.18 \pm 0.39$ & $2.88 \pm 1.05 \dagger$ & $1.27 \pm 1.10 \dagger \neq$ & $<0.001$ \\
\hline $\mathrm{CHA}_{2} \mathrm{DS}_{2}$-VASc score & $0.82 \pm 0.92$ & $4.15 \pm 1.48 \dagger$ & $2.14 \pm 1.63 \dagger \neq$ & $<0.001$ \\
\hline Congestive heart failure, n (\%) & $0(0)$ & $4(12)$ & $15(24)$ & $<0.001$ \\
\hline Hypertension, n (\%) & $0(0)$ & $18(55)$ & $37(59)$ & $<0.001$ \\
\hline Age $\geq 75$ years, $n(\%)$ & $8(16)$ & $7(21)$ & $11(17)$ & 0.83 \\
\hline Diabetes mellitus, n (\%) & $0(0)$ & $4(12)$ & $11(17)$ & $<0.001$ \\
\hline Dyslipidemia, n (\%) & $0(0)$ & $16(48)$ & $14(22)$ & $<0.001$ \\
\hline Stroke/TIA, n (\%) & $0(0)$ & $32(97)$ & $3(5)$ & $<0.001$ \\
\hline Peripheral artery disease, $\mathrm{n}(\%)$ & $0(0)$ & $2(6)$ & $5(8)$ & 0.046 \\
\hline $\mathrm{eGFR}\left(\mathrm{mL} / \mathrm{min} / 1.73 \mathrm{~m}^{2}\right)$ & $74 \pm 23$ & $64 \pm 23^{*}$ & $68 \pm 17$ & 0.060 \\
\hline \multicolumn{5}{|l|}{ Cardiac medications } \\
\hline Digitalis, n (\%) & $0(0)$ & $0(0)$ & $0(0)$ & - \\
\hline Diuretics, n (\%) & $0(0)$ & $3(9)$ & $10(16)$ & 0.013 \\
\hline Nitrates, n (\%) & $0(0)$ & $2(6)$ & $0(0)$ & 0.031 \\
\hline ARBs/ACEls, n (\%) & $0(0)$ & $12(36)$ & $23(37)$ & $<0.001$ \\
\hline Calcium channel blockers, n (\%) & $0(0)$ & $11(33)$ & $20(32)$ & $<0.001$ \\
\hline Beta-blockers, n (\%) & $0(0)$ & $3(9)$ & $21(33)$ & $<0.001$ \\
\hline Antiarrhythmic drugs, n (\%) & $0(0)$ & $0(0)$ & $20(32)$ & $<0.001$ \\
\hline
\end{tabular}

Values are mean ( \pm SD) or number of subjects (\%)

ACEI Indicates angiotensin converting enzyme inhibitors, ARB Angiotensin receptor blockers, eGFR Estimated glomerular filtration rate, and TIA transient ischemic attack

${ }^{*} P<0.05$ and $+P<0.01$ vs Healthy controls; $§ P<0.05$ and $¥ P<0.01$ vs Disease controls 
Table 2 Echocardiographic data of the study groups

\begin{tabular}{|c|c|c|c|c|}
\hline Parameters & $\begin{array}{l}\text { Healthy controls } \\
(n=50)\end{array}$ & $\begin{array}{l}\text { Disease controls } \\
(n=33)\end{array}$ & $\begin{array}{l}\text { PAF patients } \\
(n=63)\end{array}$ & $P$ \\
\hline LA diameter $(\mathrm{mm})$ & $32 \pm 5$ & $40 \pm 7 \dagger$ & $43 \pm 7+$ & $<0.001$ \\
\hline LA volume $(\mathrm{mL})$ & $32 \pm 10$ & $44 \pm 10 \dagger$ & $49 \pm 15 t$ & $<0.001$ \\
\hline $\mathrm{LA}$ volume index $\left(\mathrm{mL} / \mathrm{m}^{2}\right)$ & $19 \pm 6$ & $27 \pm 5+$ & $28 \pm 9+$ & $<0.001$ \\
\hline LV end-diastolic dimension (mm) & $42 \pm 5$ & $47 \pm 7 \dagger$ & $49 \pm 7 \dagger$ & $<0.001$ \\
\hline LV ejection fraction (\%) & $65 \pm 5$ & $61 \pm 12$ & $62 \pm 8$ & 0.088 \\
\hline Thickness of IVS (mm) & $9 \pm 1$ & $10 \pm 2 \dagger$ & $10 \pm 2+$ & $<0.001$ \\
\hline Thickness of posterior wall (mm) & $9 \pm 1$ & $10 \pm 1 \dagger$ & $9 \pm 2+\S$ & $<0.001$ \\
\hline LV mass $(\mathrm{g})$ & $120 \pm 29$ & $177 \pm 65+$ & $171 \pm 65+$ & $<0.001$ \\
\hline LV mass index $\left(\mathrm{g} / \mathrm{m}^{2}\right)$ & $73 \pm 14$ & $108 \pm 33 \dagger$ & $98 \pm 30+$ & $<0.001$ \\
\hline LV hypertrophy (\%) & $0(0)$ & $17(52)$ & $17(27)$ & $<0.001$ \\
\hline E velocity $(\mathrm{cm} / \mathrm{s})$ & $63 \pm 13$ & $60 \pm 23$ & $64 \pm 17$ & 0.59 \\
\hline A velocity $(\mathrm{cm} / \mathrm{s})$ & $71 \pm 20$ & $80 \pm 25$ & $61 \pm 23^{*} \neq$ & 0.001 \\
\hline$E / A$ & $0.95 \pm 0.33$ & $0.83 \pm 0.46^{*}$ & $1.21 \pm 0.56^{*} \neq$ & $<0.001$ \\
\hline Deceleration time (ms) & $213 \pm 56$ & $224 \pm 68$ & $205 \pm 70$ & 0.41 \\
\hline$E^{\prime}$, septal (ms) & $7.7 \pm 2.3$ & $6.1 \pm 2.5 \dagger$ & $7.7 \pm 2.4 \neq$ & $<0.001$ \\
\hline$E^{\prime}$, lateral (ms) & $10.3 \pm 3.1$ & $7.4 \pm 2.9+$ & $9.5 \pm 2.8 \neq$ & $<0.001$ \\
\hline Averaged $E^{\prime}$ (ms) & $9.0 \pm 2.5$ & $6.7 \pm 2.6 \dagger$ & $8.6 \pm 2.3 \neq$ & $<0.001$ \\
\hline$A^{\prime}$, septal (ms) & $10.0 \pm 1.7$ & $8.8 \pm 2.2^{*}$ & $7.6 \pm 2.6+\S$ & $<0.001$ \\
\hline$A^{\prime}$, lateral (ms) & $10.8 \pm 2.5$ & $9.5 \pm 2.6^{*}$ & $8.0 \pm 3.0+\S$ & $<0.001$ \\
\hline Averaged $A^{\prime}$ (ms) & $10.4 \pm 1.8$ & $9.2 \pm 2.3^{*}$ & $7.8 \pm 2.7+\S$ & $<0.001$ \\
\hline Averaged E/E', & $7.4 \pm 2.3$ & $10.0 \pm 5.4$ & $7.9 \pm 2.8$ & 0.086 \\
\hline Averaged $E^{\prime} / A^{\prime}$ & $0.90 \pm 0.33$ & $0.79 \pm 0.42$ & $1.27 \pm 0.63 \dagger \neq$ & $<0.001$ \\
\hline
\end{tabular}

Values are mean $( \pm$ SD) or number of subjects (\%)

IVS Indicates interventricular septum

${ }^{*} P<0.05$ and $+P<0.01$ vs Healthy controls; $\S P<0.05$ and $\ddagger P<0.01$ vs Disease controls

\section{Comparisons of AEMD between the study groups}

Figure 4 compares AEMD-related variables for the 3 groups. PAF patients $(75 \pm 23 \mathrm{~ms})$ had a longer period of AEMD, the lateral EMD in particular, compared with disease $(62 \pm 22 \mathrm{~ms}, P=0.009)$ and healthy $(54 \pm 24 \mathrm{~ms}$, $P<0.001)$ controls. The septal EMD and intra-LA EMD were not prolonged enough to discriminate between PAF patients and disease controls.
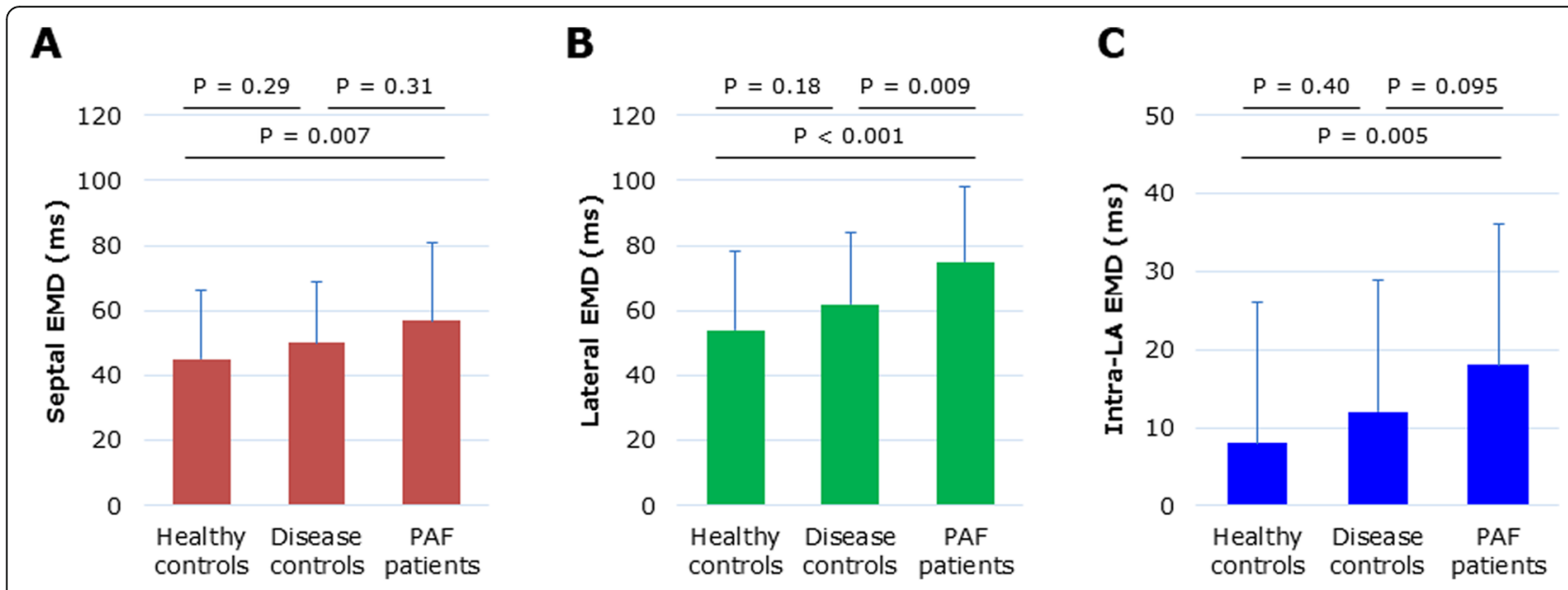

Fig. 4 Comparisons of the septal EMD (a), lateral EMD (b), and Intra-LA EMD (c) between the study groups. Data are shown in mean ( \pm SD) 
Potential usefulness of AEMD for identifying PAF patients For the total population $(n=146)$, usefulness of AEMDrelated variables for identifying PAF patients was assessed by using ROC analysis. As shown in Fig. 5a, the lateral EMD had larger AUC compared with the septal EMD $(P=0.004)$ and intra-LA EMD $(P=0.098)$. The subsequent analysis, examining relative usefulness of the lateral EMD to LA volume index and averaged A', showed no significant differences in AUCs of these indices (Fig. 5b). With a cut-off value of the lateral EMD set at $\geq 67 \mathrm{~ms}$, the sensitivity, specificity, and positive predictive value for identifying PAF patients were $70,66 \%$, and $61 \%$, respectively.

Table 3 shows the results of logistic regression analysis for identifying PAF patients. With univariate analysis, variables that significantly related to the PAF condition $(P<0.05)$ were body mass index, LA volume index, averaged A', and the lateral EMD. Multivariate analysis revealed that the lateral EMD (OR 1.25, 95\%CI 1.03-1.52, $P=0.023$ ), along with LA volume index (OR 2.25, 95\%CI 1.44-3.51, $P<0.001$ ), was one of the significant independent associate of identifying PAF patients.

\section{Discussion}

The main finding of the present study was that AEMD, particularly for the lateral side, was prolonged in PAF patients compared not only with the healthy individuals but also with MRFs patients (considered to be at highrisk for $\mathrm{AF}$ ) and that with $\mathrm{ROC}$ and multivariate analysis, the lateral EMD had noninferiority to LA volume index, known as a strong predictor of AF, for identifying PAF patients.

\section{Previous studies on AEMD and AF}

There are several reports on the relationship between AEMD and AF. Ari et al. initially reported that in 50 patients with persistent AF who underwent successful electrical cardioversion, a relatively short AEMD was associated with maintained sinus rhythm at 1-month follow-up [7]. They also found that the lateral EMD was one of the significant predictors of AF recurrence, along with LA volume index and LV inflow A wave velocity [7]. In 108 PAF patients and 52 healthy controls, Hoshi et al. found that prolonged AEMD (81\%) was frequently associated with PAF, the percentage of which was greater than LA volume index (53\%) and lateral A' (52\%) [8]. Results of ours were consistent with, and supportive of, those in these previous studies $[7,8]$. Among patients with prior ischemic stroke, the clinical background similar to our MRFs patients, AEMD was shown to be prolonged
A

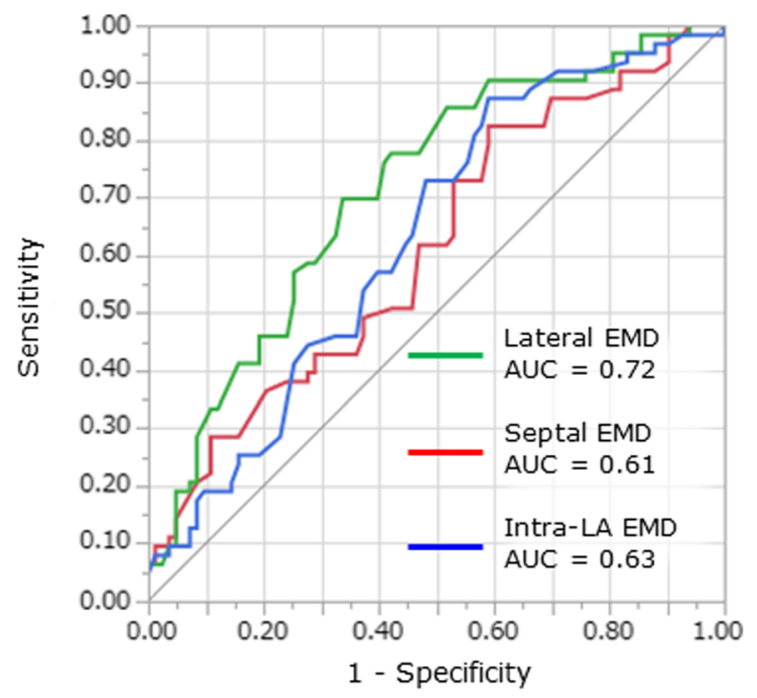

Lateral EMD vs Septal EMD

Lateral EMD vs Intra-LA EMD

Septal EMD vs Intra-LA EMD
$P=0.004$

$\mathrm{P}=0.098$

$P=0.79$
B

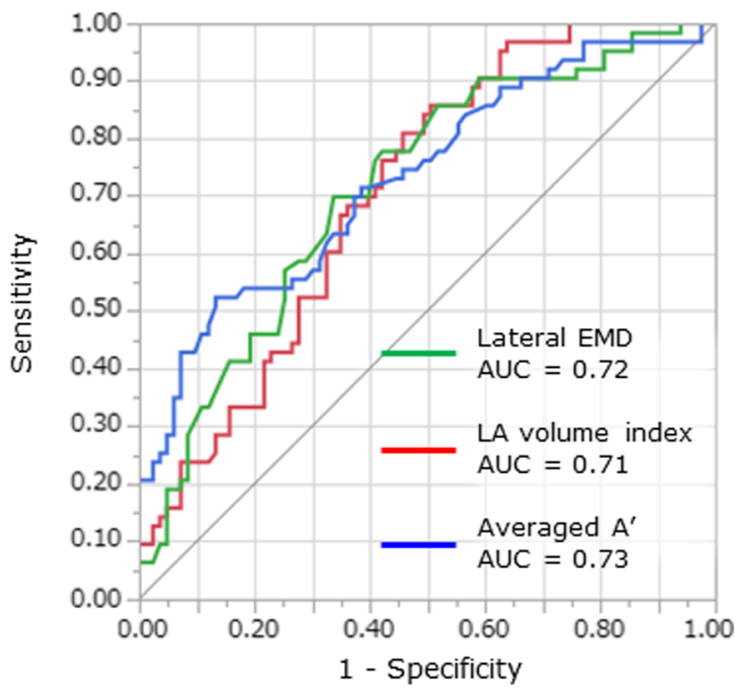

Lateral EMD vs LA volume index

Lateral EMD vs Averaged $\mathrm{A}^{\prime}$

$\mathrm{P}=0.89$

$P=0.76$

LA volume index vs Averaged $A^{\prime} \quad P=0.66$

Fig. 5 ROC analysis for identifying PAF patients, comparing AUCs of AEMD-related variables (a), and AUCs of the lateral EMD, LA volume index, and the averaged $A^{\prime}(\mathbf{b})$ 
Table 3 Univariate and multivariate logistic regression analysis for identifying PAF patients

\begin{tabular}{|c|c|c|c|c|c|c|}
\hline \multirow[t]{2}{*}{ Parameters } & \multicolumn{3}{|c|}{ Univariate analysis } & \multicolumn{3}{|c|}{ Multivariate analysis } \\
\hline & $\mathrm{OR}$ & $95 \% \mathrm{Cl}$ & $P$ & $\mathrm{OR}$ & $95 \% \mathrm{Cl}$ & $P$ \\
\hline Age (per 10 years) & 0.98 & $0.77-1.24$ & 0.85 & 1.33 & $0.87-2.05$ & 0.19 \\
\hline Body mass index per 5.0 & 2.18 & $1.34-3.56$ & 0.002 & 1.99 & $1.02-3.88$ & 0.044 \\
\hline $\mathrm{CHA}_{2} \mathrm{DS}_{2}$-VASc score & 1.0 & $0.84-1.19$ & 1.0 & 0.77 & $0.56-1.06$ & 0.11 \\
\hline eGFR (per $10 \mathrm{~mL} / \mathrm{min} / 1.73 \mathrm{~m}^{2}$ ) & 0.94 & $0.80-1.11$ & 0.49 & 1.25 & $0.95-1.64$ & 0.11 \\
\hline LA volume index (per $5 \mathrm{~mL} / \mathrm{m}^{2}$ ) & 1.96 & $1.43-2.69$ & $<0.001$ & 2.25 & $1.44-3.51$ & $<0.001$ \\
\hline LV hypertrophy $(=1)$ & 1.43 & $0.66-3.10$ & 0.36 & 0.38 & $0.11-1.28$ & 0.12 \\
\hline Averaged $A^{\prime}$ & 0.68 & $0.58-0.80$ & $<0.001$ & 0.68 & $0.55-0.84$ & $<0.001$ \\
\hline Lateral EMD (per 10 ms) & 1.41 & $1.20-1.65$ & $<0.001$ & 1.25 & $1.03-1.52$ & 0.023 \\
\hline
\end{tabular}

Abbreviations are the same as in Table 1

(not as much prolonged as in AF patients) compared with normal controls [13].

\section{Potential mechanisms of prolonged AEMD in AF}

Longer AEMD implies more heterogeneous propagation impulse within the atria that may be compromised by fatty replacement [17]. Although no experimental evidence has existed on this assumption, prolonged atrial conduction time is found to be associated with increased LA diameter and reduced LA systolic function, supporting the notion that AEMD reflects structural and electrophysiological remodeling of the atrium [18-20]. Another reason for the relatively prolonged AEMD in PAF patients may be related to an effect of inflammatory cytokines [21]. Systemic inflammation reportedly causes subclinical cardiac damage even in an early phase of atherosclerosis [22]. Some disorders in which inflammation underlies, such as diabetes mellitus and ulcerative colitis, are shown to be associated with AEMD prolongation [9-11].

Nevertheless, not all PAF patients were considered to have significant atrial involvement with irreversible atrial mechanical function. Because of the paroxysmal nature, some patients might have atrial mechanical function halfway recovered at the time of echocardiography. This may be supported by the finding that in PAF patients, E/e' was not as high as expected while their LV filling pattern showed "restrictive" [23]. Whether AEMD shortens concurrently with improved atrial mechanical function over time awaits further investigations.

In the present study, only the lateral EMD emerged as a significant predictor of identifying PAF patients. From a histopathological viewpoint, myocytes of the left atrium are irregularly arranged compared with those of the right atrium [24]. Given that degenerated atrial tissue is associated with atrial current running in a non-uniform manner
[25], AEMD prolongation greater at the lateral side compared with the septal is plausible, further suggesting that the lateral EMD is more likely related to AF vulnerability.

\section{Clinical implications}

To the best of our knowledge, this is the first report describing the significance of AEMD that is analyzed along with "disease controls". One important finding from our results is that AEMD was prolonged in PAF patients compared with MRFs patients who had a certain degree of LA enlargement and diastolic dysfunction. Underlying mechanisms for the different AEMD between the groups despite similar clinical and functional features remain unclear, but may deserve to be addressed with further investigations.

\section{Limitations}

The single-center, cross-sectional study was an inherent limitation in this study. We used "PAF" as a surrogate for AF prediction or recurrence and thus our results cannot be extrapolated to other situations. Follow-up examinations were not performed. This was because in addition to the small number of patients, a certain number of patients had experienced stroke or received anti-arrhythmic drugs, which might preclude meaningful results that would be drawn. Another limitation was that the possibility of occult PAF occurring among patients in disease controls could not be excluded. However, no patients with MRFs had been reported to have AF during hospitalization, to have intracardiac thrombus, or to ever be anticoagulated. Other variables that might have related to AF were not available, such as the right-sided AEMD or a novel index of LA strain [26]. Finally, influence of anti-arrhythmic drugs on AEMD remains to be evaluated.

\section{Conclusions}

The preset study evaluated usefulness of AEMD for identifying PAF patients. We found that AEMD, 
particularly for the lateral side, was prolonged to a more extent in PAF patients compared with healthy subjects in addition to MRFs patients. Also, AEMD was shown to have noninferiority to LA volume index in identifying PAF patients. Prospective studies, with a larger number of subjects, are needed to confirm our results and to identify thresholds at which any abnormal values of AEMD alter clinical management in patients with various cardiovascular conditions.

\section{Abbreviations \\ AEMD: Atrial electromechanical delay; AF: Atrial fibrillation; AUC: Area under curve; EMD: Electromechanical delay; LA: Left atrial; LV: Left ventricular; MRFs: Multiple cardiovascular risk factors; PAF: Paroxysmal atrial fibrillation; ROC: Receiver operating characteristic}

\section{Acknowledgements}

We obtained permission to acknowledge from all those mentioned as the following:

We are grateful to Atsuko Nishiguchi and Keiji Nishimura of Osaka Medical College Hospital for their echocardiographic expertise, and for acquiring as well as measuring data on ultrasound including AEMD.

\section{Authors' contributions}

$\mathrm{TI}$ and KA designed the study, analyzed the data, and wrote the initial draft of the manuscript. YK and KS contributed to the interpretation of data. MH gave their final approval to the manuscript. All other authors critically reviewed the manuscript. The author(s) read and approved the final manuscript.

\section{Funding}

No funding for the current study was received.

\section{Availability of data and materials}

All data generated or analyzed during this study are included in this published article [and its supplementary information files].

\section{Ethics approval and consent to participate}

This study was approved by the ethics review board of Osaka Medical College with notification for guaranteed withdrawal of participants on the website providing means of "opt-out" (No. 2194-01).

\section{Consent for publication}

Our manuscript does not contain any individual person's data in any form (including individual details, images or videos).

\section{Competing interests}

The authors declare that they have no competing interests.

Received: 3 April 2020 Accepted: 18 June 2020

Published online: 22 June 2020

\section{References}

1. Wilke T, Groth A, Mueller S, Pfannkuche M, Verheyen F, Linder R, et al. Incidence and prevalence of atrial fibrillation: an analysis based on 8.3 million patients. Europace. 2013;15:486-93. https://doi.org/10.1093/ europace/eus333.

2. Dzeshka MS, Shantsila A, Shantsila E, Lip GYH. Atrial fibrillation and hypertension. Hypertension. 2017;70:854-61. https://doi.org/10.1161/ HYPERTENSIONAHA.117.08934.

3. Fornengo C, Antolini M, Frea S, Gallo C, Grosso Marra W, Morello M, et al. Prediction of atrial fibrillation recurrence after cardioversion in patients with left-atrial dilation. Eur Heart J Cardiovasc Imaging. 2015;16:335-41. https:// doi.org/10.1093/ehjci/jeu193.

4. Njoku A, Kannabhiran M, Arora R, Reddy P, Gopinathannair R, Lakkireddy D, et al. Left atrial volume predicts atrial fibrillation recurrence after radiofrequency ablation: a meta-analysis. Europace. 2018;20:33-42. https:// doi.org/10.1093/europace/eux013.

5. Faustino A, Providência R, Barra S, Paiva L, Trigo J, Botelho A, et al. Which method of left atrium size quantification is the most accurate to recognize thromboembolic risk in patients with non-valvular atrial fibrillation? Cardiovasc Ultrasound. 2014;12:28. https://doi.org/10.1186/1476-7120-12-28.

6. Deftereos S, Kossyvakis C, Efremidis M, Bouras G, Panagopoulou V, Papadimitriou $C$, et al. Interatrial conduction time and incident atrial fibrillation: a prospective cohort study. Heart Rhythm. 2014;11:1095-101. https://doi.org/10.1016/j.hrthm.2014.03.053.

7. Ari H, Ari S, Akkaya M, Aydin C, Emlek N, Sarigül OY, et al. Predictive value of atrial electromechanical delay for atrial fibrillation recurrence. Cardiol J. 2013; 20:639-6. https://doi.org/10.5603/CJ.2013.0164

8. Hoshi Y, Nozawa Y, Ogasawara M, Yuda S, Sato S, Sakasai T, et al. Atrial electromechanical interval may predict cardioembolic stroke in apparently low risk elderly patients with paroxysmal atrial fibrillation. Echocardiography. 2014;31:140-8. https://doi.org/10.1111/echo.12329.

9. Acar G, Akcay A, Sokmen A, Ozkaya M, Guler E, Sokmen G, et al. Assessment of atrial electromechanical delay, diastolic functions, and left atrial mechanical functions in patients with type 1 diabetes mellitus. J Am Soc Echocardiogr. 2009;22:732-8. https://doi.org/10.1016/j.echo.2009.03.028.

10. Nar G, Ergul B, Aksan G, Inci S. Assessment of atrial electromechanical delay and left atrial mechanical functions in patients with ulcerative colitis. Echocardiography. 2016;33:970-6. https://doi.org/10.1111/echo.13213.

11. Aksan G, Nar G, Soylu K, Inci S, Yuksel S, Ocal HS, et al. Assessment of atrial electromechanical delay and left atrial mechanical functions in patients with psoriasis vulgaris. Echocardiography. 2015;32:615-22. https://doi.org/10. 1111/echo.12706.

12. Ilter A, Kırış A, Kaplan \$̧, Kutlu M, Şahin M, Erem C, Civan N, et al. Atrial conduction times and left atrium mechanical functions in patients with active acromegaly. Endocrine. 2015;48:653-60. https://doi.org/10.1007/ s12020-014-0348-1.

13. Akıl MA, Akıl E, Bilik MZ, Oylumlu M, Acet H, Yıldız A, Akyüz A, et al. The relationship between atrial electromechanical delay and left atrial mechanical function in stroke patients. Anatol J Cardiol. 2015;15:565-70. https://doi.org/10.5152/akd.2014.5558.

14. Hart RG, Catanese L, Perera KS, Ntaios G, Connolly SJ. Embolic stroke of undetermined source: a systematic review and clinical update. Stroke. 2017; 48:867-72. https://doi.org/10.1161/STROKEAHA.116.016414.

15. Lang RM, Badano LP, Mor-Avi V, Afilalo J, Armstrong A, Ernande L, et al. Recommendations for cardiac chamber quantification by echocardiography in adults: an update from the American Society of Echocardiography and the European Association of Cardiovascular Imaging. Eur Heart J Cardiovasc Imaging. 2015;16:233-70. https://doi.org/10.1093/ehjci/jev014.

16. Nagueh SF, Middleton KJ, Kopelen HA, Zoghbi WA, Quiñones MA, et al. Doppler tissue imaging: a noninvasive technique for evaluation of left ventricular relaxation and estimation of filling pressures. J Am Coll Cardiol. 1997:30:1527-33.

17. Kottkamp H. Human atrial fibrillation substrate: towards a specific fibrotic atrial cardiomyopathy. Eur Heart J. 2013;34:2731-8. https://doi.org/10.1093/ eurheartj/eht194.

18. Raybaud F, Camous JP, Benoit P, Dolisi C, Baudouy M. Relationship between interatrial conduction times and left atrial dimension in patients undergoing atrioventricular stimulation. Pacing Clin Electrophysiol. 1995;18:447-50.

19. Thomas L, Levett K, Boyd A, Leung DY, Schiller NB, Ross DL. Changes in regional left atrial function with aging: evaluation by Doppler tissue imaging. Eur J Echocardiogr. 2003:4:92-100.

20. Merckx KL, De Vos CB, Palmans A, Habets J, Cheriex EC, Crijns HJ, et al. Atrial activation time determined by transthoracic Doppler tissue imaging can be used as an estimate of the total duration of atrial electrical activation. J Am Soc Echocardiogr. 2005;18:940-4.

21. Harada M, Van Wagoner DR, Nattel S. Role of inflammation in atrial fibrillation pathophysiology and management. Circ J. 2015;79:495-502. https://doi.org/10.1253/circj.CJ-15-0138.

22. Theocharidou E, Gossios TD, Giouleme O, Athyros VG, Karagiannis A. Carotid intima-media thickness in patients with inflammatory bowel disease: a systematic review. Angiology. 2014;65:284-93. https://doi.org/10.1177/ 0003319713477471

23. Yamada H, Donal E, Kim YJ, Agler DA, Zhang Y, Greenberg NL, et al. The pseudorestrictive pattern of transmitral Doppler flow pattern after conversion of atrial fibrillation to sinus rhythm: is atrial or ventricular dysfunction to blame? J Am Soc Echocardiogr. 2004;17:813-8.

24. Hari KJ, Nguyen TP, Soliman EZ. Relationship between P-wave duration and the risk of atrial fibrillation. Expert Rev Cardiovasc Ther. 2018:16:837-43. https://doi.org/10.1080/14779072.2018.1533814. 
25. Anderson $\mathrm{RH}$, Cook AC. The structure and components of the atrial chambers. Europace. 2007;9(Suppl 6):vi3-9.

26. Yasuda R, Murata M, Roberts R, Tokuda H, Minakata Y, Suzuki K, et al. Left atrial strain is a powerful predictor of atrial fibrillation recurrence after catheter ablation: study of a heterogeneous population with sinus rhythm or atrial fibrillation. Eur Heart J Cardiovasc Imaging. 2015;16:1008-14. https:// doi.org/10.1093/ehjci/jev028.

\section{Publisher's Note}

Springer Nature remains neutral with regard to jurisdictional claims in published maps and institutional affiliations.

Ready to submit your research? Choose BMC and benefit from:

- fast, convenient online submission

- thorough peer review by experienced researchers in your field

- rapid publication on acceptance

- support for research data, including large and complex data types

- gold Open Access which fosters wider collaboration and increased citations

- maximum visibility for your research: over $100 \mathrm{M}$ website views per year

At $B M C$, research is always in progress.

Learn more biomedcentral.com/submissions 